\title{
Single fraction of accelerated partial breast irradiation in the elderly: early clinical outcome
}

Rémy Kinj ${ }^{1}$, Marie-Eve Chand ${ }^{1}$, Jocelyn Gal², Mathieu Gautier ${ }^{1}$, Lucile Montagné ${ }^{1}$, Daniel Lam Cham Kee ${ }^{1}$ and Jean Michel Hannoun-Lévi ${ }^{1 *}$

\begin{abstract}
Background: To analyze the clinical outcome of elderly women with early breast cancer who underwent accelerated partial breast irradiation (APBI) based on a post-operative single fraction of multicatheter interstitial high dose-rate brachytherapy (MIB).

Methods: A single institution retrospective cohort study was performed focusing on elderly patients ( $\geq 65$ years old) presenting a low-risk breast carcinoma treated by lumpectomy plus axillary evaluation followed by MIB. A single fraction of $16 \mathrm{~Gy}$ was prescribed on the $100 \%$ isodose. Clinical outcome at 3 years was reported based on local relapse free survival (3-y LRFS), specific survival (SS) and overall survival (OS). Acute $(<180$ days after $\mathrm{APBI}$ ) and late toxicity were evaluated. Cosmetic results were clinically evaluated by the physician.

Results: Between January 2012 and August 2015, 48 women (51 lesions) were treated. Median age was 77. 7 years (range: 65-92) with a median tumor size of $12 \mathrm{~mm}$ (range: 3-32). Five patients (pts) presented an axillary lymph node involvement (4 Nmic, $1 \mathrm{N1}$ ). Invasive ductal carcinoma was the most frequent histology type (86.3\%). With a median follow-up of 40 months (range: 36-42), no local relapse occurred while 1 pt. developed axillary relapse (2.1\%). The 3-y LRFS, SS and OS rates were 100\%, 100\% and $93.1 \%$ respectively. Forty-five acute events were remained. The most frequent acute toxicity was grade (G) 1 hyperpigmentation (26.7\%), 3 pts. (6.3\%) presented G3 acute toxicity (2 breast hematomas, 1 breast abscess). No $\geq$ G3 late toxicity was observed while 15 late toxicities occurred (G1: 13 events - 86.7\%) mainly breast fibrosis). The rate of excellent cosmetic outcome was $76.4 \%$.

Conclusion: We reported promising and encouraging clinical outcome of a post-operative single fraction of MIB ABPI in the elderly. This approach leads to consider a SFAPBI as an attractive alternative to intra-operative radiation therapy while all the patients will be good candidates for APBI in regards to the post-operative pathological report. More mature results (number of patients and follow-up) are needed.
\end{abstract}

Keywords: Breast cancer, Elderly, Accelerated partial breast irradiation, Brachytherapy

\footnotetext{
*Correspondence: jean-michel.hannoun-levi@nice.unicancer.fr

'Department of Radiation Oncology, Centre Antoine Lacassagne - University

of Cote d'Azur, 33 avenue de Valombrose, 06000 Nice, France

Full list of author information is available at the end of the article
}

(c) The Author(s). 2018 Open Access This article is distributed under the terms of the Creative Commons Attribution 4.0 International License (http://creativecommons.org/licenses/by/4.0/), which permits unrestricted use, distribution, and reproduction in any medium, provided you give appropriate credit to the original author(s) and the source, provide a link to the Creative Commons license, and indicate if changes were made. The Creative Commons Public Domain Dedication waiver (http://creativecommons.org/publicdomain/zero/1.0/) applies to the data made available in this article, unless otherwise stated. 


\section{Background}

During the last half of century, breast cancer therapeutics progressed steadily and rapidly. In the management of localized breast cancers, total mastectomy has gradually given way to conservative surgical treatments followed by adjuvant radiotherapy. The conservative therapeutic approach is now considered as a standard of care for T1-2 breast cancer [1, 2]. However, the standard adjuvant radiotherapy schedule (25 to 30 fractions) generates much transportation that can be difficult mainly for elderly women. Even using hypofractionated regimen (15 to 16 fractions) [3-5] in place of standard schedule, adjuvant breast irradiation can alter the quality of life and sometimes the adhesion to the treatment. Furthermore, a higher number of transportations generates additional costs for health insurance.

Accelerated partial breast irradiation (APBI) appears as a natural continuity in the process of therapeutic de-escalation. American Society of Radiation Oncology (ASTRO) and Groupe Européen de Curiethérapie of the European Society for Radiotherapy and Oncology (GECESTRO) have considered that, in a well selected population, described as "suitable" (ASTRO) and "low-risk" (ESTRO), adjuvant APBI can be proposed [6, 7]. After two decades of clinical research, APBI is now recognized as an efficient and safe adjuvant treatment for low-risk breast cancer $[8,9]$.

The aim of this study was to report the early clinical outcome of APBI in the elderly with early breast cancer treated by a post-operative single fraction of MIB APBI (sfAPBI).

\section{Methods}

\section{Patient selection}

This is a single institution retrospective study including elderly patients presenting with low-risk breast cancer who underwent lumpectomy plus axillary evaluation followed by a single fraction of high-dose rate (HDR) MIB APBI. The patient cohort combined women enrolled in a prospective phase I/II trial (SiFEBI; Clinical.gov \#NCT01727011, [10]) and patients previously treated before the SiFEBI trial opening. Briefly, inclusion criteria were as follows: elderly women 65 years and older, histologically proven breast carcinoma with free surgical margins, negative axillary evaluation. Patients were excluded in case of: sarcoma or lymphoma histology, metastatic dissemination. Data were collected from the Antoine Lacassagne Cancer Center institutional database. All the patients treated out of the SiFEBI trial, had the choice between adjuvant WBI and sfAPBI. All APBI indications were validated by the local breast oncologist committee. Patients treated outside of the SiFEBI trial (Clinical.gov \#NCT01727011) were carefully selected and fully informed about the new irradiation procedure (advantages and disadvantages) compared to the standard protocol of external beam radiation therapy currently used in our institution. All those patients signed consent form before starting the treatment.

\section{Treatments}

\section{Breast surgery}

As previously described, axillary dissection concerned Level I and II axillary lymph node area while sentinel lymph node biopsy alone was also achieved with per-operative exam and conversion to axillary dissection in case of positive biopsy. Then, lumpectomy was performed. Quality of margins was assessed by a per-operative pathological exam. Four to five clips were clamped by the surgeon to mark the tumor bed before closing the tumor bed cavity [11].

\section{Brachytherapy}

Brachytherapy was performed according to the GECESTRO Breast Cancer Working Group recommendations for MIB APBI [12]. As previously described, vectors (Sharp Needles ${ }^{\mathrm{Tm}}$; Elekta AB, Stockholm, Sweden) were placed mainly intra-operatively by the radiation oncologist using 1 to 3 planes in respect with Paris system recommendations [11]. Two days after the implant, a post implant CT $(2.5 \mathrm{~mm}$ thickness slice) was performed in order to delineate the clinical target volume (CTV) based on clips and surgical cavity (if visible) including a total safety margin of about $2 \mathrm{~cm}$ (sum of the resection margin size and "added" safety margins size) [13]. Then, the dose distribution was optimized manually (OncentraBrachy; Elekta, Sweden) by varying time and stop position of the radioactive source. A single fraction of 16 Gy was prescribed to the $100 \%$ isodose. This dose was calculated considering an $\alpha / \beta$ ratio of 3.4 Gy for breast late toxicity and 4.6 for local control [14]. According to the linear quadratic model, the equivalent dose at 2 Gy (EQD2) for a single fraction of 16 Gy is equal to 53 Gy with a $\alpha / \beta=4$ Gy $[15,16]$. Dose constraints were as follow: $\mathrm{D} 90 \% \geq 105 \%$ of the prescribed dose, $\mathrm{D} 100 \% \geq 75 \%, \mathrm{~V} 100>95 \%$ of the CTV, V150 $\leq 40 \%$, V200 $\leq 15 \%$; dose non-homogeneity ratio (DNR) $\leq 35 \%$ [10]. For organ at risk (skin and thoracic wall), the maximum skin-dose was $<75 \%$ of the prescribed dose while the maximum rib dose was $<100 \%$ of the prescribed dose.

\section{Systemic therapy}

Systemic therapies such as adjuvant chemotherapy and/ or hormonal treatments were dispensed according to the protocols used in the Antoine Lacassagne Cancer Center. 


\section{Follow up}

The radiation oncologist performed iterative monthly post-brachytherapy clinics during 3 months (acute brachytherapy side effects). Then, clinical surveillance was performed alternatively with the surgeon twice a year with a yearly mammogram. Acute ( $<180$ days after treatment) and late toxicities were evaluated by Common Terminology Criteria for Adverse Event v3 (CTCAE.V3.0) [17]. Cosmetic evaluation was performed according to Harvard criteria [18].

\section{Statistical analysis}

Description of the study population and of the different investigated parameters was made using absolute and relative frequencies for the qualitative data and summarized using descriptive statistics such as median, extreme for quantitative data. Survival time was defined between the surgery date and the event date. Local relapse free-survival (LRFS), regional relapse free-survival (RRFS), specific (SS) and overall survivals (OS) were estimated using the Kaplan-Meier method. Patients still alive were censored at the date of last follow-up. Median follow-up with $95 \%$ confidence intervals was calculated by reverse Kaplan-Meier method. Data entry and data management were performed on Ennov clinical ${ }^{\circ}$ system and were analyzed using R 3.2.2 for Windows ${ }^{\circ}$.

\section{Results}

\section{Patient and tumor characteristics}

Between January 2012 and August 2015, a total of 51 lesions from 48 patients (pts) were treated with a sfAPBI. Among these patients, 26 were part of the SiFEBI trial while 22 pts. were treated out of the phase II study. Patient, tumor and treatment features are detailed in Table 1. Patient median age was 77.7 years [range: 6592]. Most of patients were ECOG Performans Status (PS) 0 (85\%). The most frequent location was the upper external quadrant (39.2\%). Histological type was mainly invasive ductal carcinoma (86.2\%). The median tumor size was $12 \mathrm{~mm}$ [range: 3-32] while, 4 pts. presented with a microscopic node involvement (Nmic) and $1 \mathrm{pt}$. was classified N1. The median surgical margin was $5 \mathrm{~mm}$ [range: 1-10]. One lesion was associated with peri-neural invasion. All the tumors but three had positive hormonal receptor status while Her-2 status was over-expressed in $9.8 \%$.

\section{Treatment characteristics}

A median number of 11 vectors [range: 5-15] on 2 planes [range: 1-3] were implanted (depending on the thickness and location of the target volume), mainly intra-operatively (92.2\%). The median time between surgery and sfAPBI was 7 days [range: 1-63]. The median CTV was 44 cc [range: 11-124]. The median V100\%
Table 1 Patients, lesions and treatment characteristics

\begin{tabular}{|c|c|c|}
\hline Patient features & $\begin{array}{l}\text { Number of } \\
\text { patients }\end{array}$ & $\% /(\min -\max )$ \\
\hline \multicolumn{3}{|l|}{ Patients included in SiFEBI trial } \\
\hline Yes & 26 & 54.2 \\
\hline No & 22 & 45.8 \\
\hline Mean age (years) & 77.7 & $(65.2-92.3)$ \\
\hline \multicolumn{3}{|l|}{ ECOG-Performans Status } \\
\hline 0 & 41 & 85.5 \\
\hline 1 & 7 & 14.5 \\
\hline \multicolumn{3}{|l|}{ Tumor side } \\
\hline Left & 28 & 54.9 \\
\hline Right & 23 & 45.1 \\
\hline \multicolumn{3}{|l|}{ Location } \\
\hline Upper external quadrant & 20 & 39.2 \\
\hline Upper internal quadrant & 5 & 9.8 \\
\hline Lower internal quadrant & 3 & 5.9 \\
\hline Lower external quadrant & 3 & 5.9 \\
\hline Junction of external quadrant & 6 & 11.8 \\
\hline Junction of internal quadrant & 3 & 5.9 \\
\hline Junction of lower quadrant & 3 & 5.9 \\
\hline Junction of upper quadrant & 6 & 11.7 \\
\hline Periareolar & 2 & 3.9 \\
\hline Median tumor size (mm) & 12 & $(3-32)$ \\
\hline \multicolumn{3}{|l|}{ Tumor stage } \\
\hline T1a & 28 & 54.9 \\
\hline $\mathrm{T} 1 \mathrm{~b}$ & 18 & 35.3 \\
\hline T1c & 5 & 9.8 \\
\hline \multicolumn{3}{|l|}{ Axillary lymph node status } \\
\hline No & 46 & 90.1 \\
\hline N1mic & 4 & 7.9 \\
\hline $\mathrm{N} 1$ & 1 & 2.0 \\
\hline \multicolumn{3}{|l|}{ Histology type } \\
\hline Invasive ductal carcinoma & 44 & 86.3 \\
\hline Invasive lobular carcinoma & 3 & 5.9 \\
\hline Other & 4 & 7.8 \\
\hline \multicolumn{3}{|l|}{ Histological grade } \\
\hline 1 & 32 & 62.7 \\
\hline 2 & 14 & 27.4 \\
\hline 3 & 5 & 9.8 \\
\hline \multicolumn{3}{|l|}{ Hormonal status } \\
\hline Positive & 48 & 94.1 \\
\hline Negative & 3 & 5.9 \\
\hline \multicolumn{3}{|l|}{ Her-2 status } \\
\hline Over-expressed & 5 & 9.8 \\
\hline Non-over-expressed & 46 & 90.2 \\
\hline
\end{tabular}


Table 1 Patients, lesions and treatment characteristics (Continued)

\begin{tabular}{lll}
\hline Patient features & $\begin{array}{l}\text { Number of } \\
\text { patients }\end{array}$ & / (min - max) \\
\hline Peri-neural invasion & 1 & 1.9 \\
Yes & 50 & 98.1 \\
No & 10 & $(5-60)$ \\
Median Ki-67 (\%) & 5 & $(1-10)$ \\
Median surg. Marg.(mm) & & \\
Implant time & 47 & 92.2 \\
Intra operative & 4 & 7.8 \\
Post-operative & 7 & $(1-63)$ \\
Median time interv. Surg./APBI (d) & 11 & $(5-15)$ \\
Median number of vectors & 2 & $(1-3)$ \\
Median number of planes & 44 & $(11-124)$ \\
Median CTV (cc) & 96 & $(86-100)$ \\
Median V100\% (\%) & 34 & $(23-48)$ \\
Median V150\% (\%) & 12 & $(8-21)$ \\
Median V200\% (\%) & 0.35 & $(0.23-0.56)$ \\
Median DNR &
\end{tabular}

Median time interv. Surg./APBI: median time between intervention and sfAPBI; Median surg. Marg.: median surgical margins; DNR: dose non-homogeneity ratio $=$ V100/V150 was 96\% [range: $86-100$ ] (Table 1). The median treated volume was 42 cc [range: 10-124].

\section{Oncological outcome}

With a median follow-up of 40 months [range: 36-42], no local relapse occurred while $1 \mathrm{pt}$. developed an axillary relapse (2.1\%). Three-year LRFS, RRFS and SS were $100 \%$, 3-year OS was 93.1\% [86.4-1] (Fig. 1).

\section{Acute and late toxicity}

Forty-five acute events were remained. The most frequent acute toxicity was grade (G) 1 hyperpigmentation (26.7\%). Three pts. presented G3 acute toxicity (2 breast hematomas, 1 breast abscess). No $\geq G 3$ late toxicity was observed while 15 late toxicities occurred (G1: 11 events [80\%]). G1 breast fibrosis and hypopigmentation of puncture site were the most frequent late side effects. The rate of excellent cosmetic outcome was $76.4 \%$. A breast asymmetry was noticed in 2 pts. (4\%) (Table 2).

\section{Discussion}

APBI is now recognized as a validated irradiation option for low-risk breast cancer [12]. The current challenge is to deliver irradiation dose in the shortest treatment duration, in the most appropriate population. From a technical point of view, 2 different APBI approaches can be proposed: Intraoperative irradiation (electron or low-energy $\mathrm{X}$ photon $[50 \mathrm{kV}]$ ) or postoperative irradiation either with brachytherapy (multicatheter interstitial

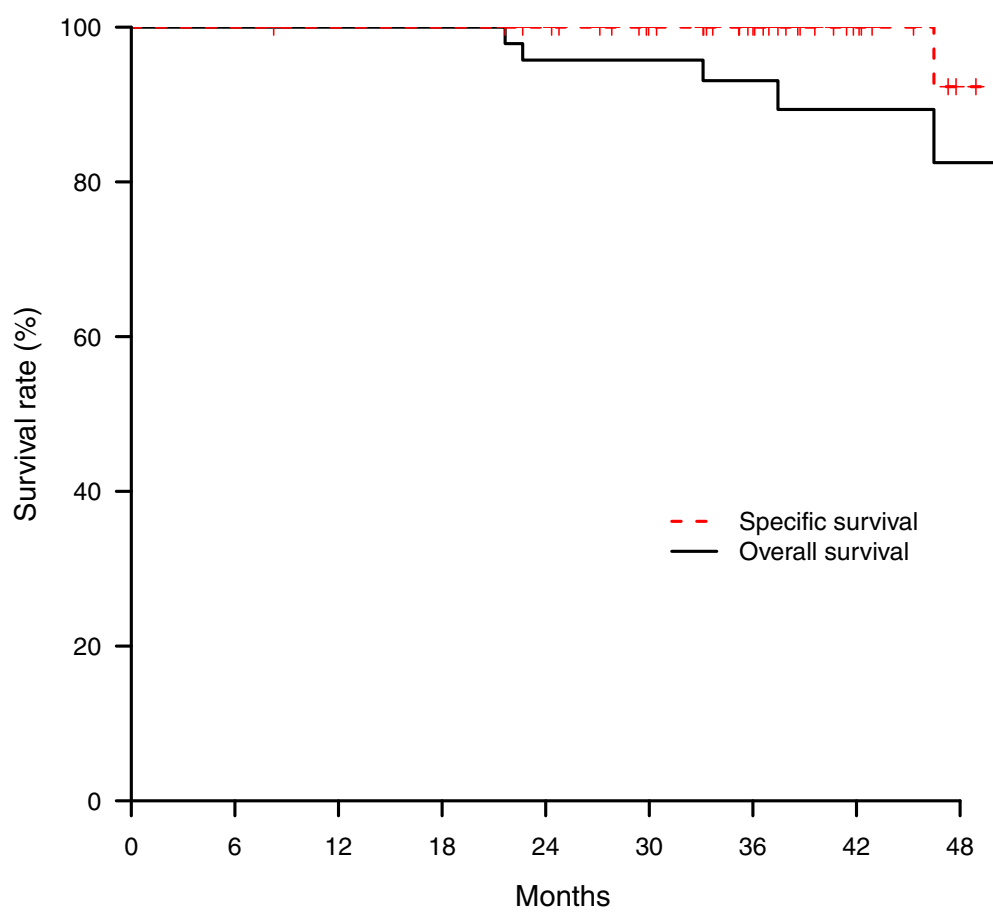

Fig. 1 Specific and overall survival 
Table 2 Acute and late toxicity outcome

\begin{tabular}{|c|c|c|}
\hline Toxicity & Number of events & $\%$ \\
\hline \multicolumn{3}{|l|}{ Acute } \\
\hline \multicolumn{3}{|l|}{ Grade 1} \\
\hline Hyperpigmentation & 12 & 26.7 \\
\hline Epithelitis & 3 & 6.7 \\
\hline Breast hematoma & 2 & 4.4 \\
\hline Other & 13 & 28.9 \\
\hline Total & 30 & 66.7 \\
\hline \multicolumn{3}{|l|}{ Grade 2} \\
\hline Breast pain & 2 & 4.4 \\
\hline Breast hematoma & 2 & 4.4 \\
\hline Skin hyperpigmentation & 2 & 4.4 \\
\hline Other & 6 & 13.3 \\
\hline Total & 12 & 26.7 \\
\hline \multicolumn{3}{|l|}{ Grade 3} \\
\hline Breast hematoma & 2 & 4.4 \\
\hline Breast infection & 1 & 2.2 \\
\hline Total & 3 & 6.7 \\
\hline Total number of events & 45 & 100 \\
\hline \multicolumn{3}{|l|}{ Late } \\
\hline \multicolumn{3}{|l|}{ Grade 1} \\
\hline Breast fibrosis & 4 & 26.7 \\
\hline Puncture site hypopig. & 5 & 33.3 \\
\hline Telangectasia & 2 & 13.3 \\
\hline Epithelitis & 1 & 6.7 \\
\hline Other & 1 & 6.7 \\
\hline Total & 13 & 86.7 \\
\hline \multicolumn{3}{|l|}{ Grade 2} \\
\hline Breast fibrosis & 2 & 13.3 \\
\hline Total number of events & 15 & 100 \\
\hline \multicolumn{3}{|l|}{ Cosmetic outcome } \\
\hline Excellent & 39 & 76.4 \\
\hline Good & 12 & 25.6 \\
\hline
\end{tabular}

Puncture site hypopig.: Puncture site hypopigmentation

brachytherapy [MIB] / balloon devices) or external beam irradiation (3D or Intensity modulated) [19]. Intraoperative irradiation (IORT) allows the optimal reduction of the treatment duration since the patient is irradiated during the lumpectomy process. However, at least 15\% of patients are partially irradiated while the definitive histology is not suitable for this treatment [20]. Consequently, those patients need a post-operative whole breast irradiation (WBI) while the intra-op APBI is considered as a "boost". Post-operative irradiation does permit treating only validated candidates for APBI due to an appropriate definitive pathological report compatible with APBI criteria while the number of transportation remains significantly higher compared to IORT. Furthermore, MIB-APBI allows best target coverage [21]. In this frame, a post-operative single fraction APBI appeared as an attractive technical option by drastically reducing the number of transportations and in the same time, alleviating the treatment related constraints mainly for elderly patients with frequent comorbidities [22].

In our study, after a median follow-up of 40 months, no local relapse was observed while SS rate was $100 \%$. Two studies already reported oncological outcome after a MIB sfAPBI. In the SiFEBI prospective phase II trial, 26 elderly patients were treated with a 16 Gy sfAPBI. After a median follow-up of 37 months, there was no local relapse [10]. Recently, Latorre et al. reported the results of 20 pts. treated with a MIB sfAPBI of 18 Gy. After a median follow-up of 20 months, there was no local relapse [23]. Other teams investigated very hypofractionnated APBI, based on different regimens ( 1 to 7 fractions in 1 to 2 consecutive days) and HDR irradiation techniques (Per-operative and balloon devices) [24-27]. The results of those studies (oncological outcome and toxicities) are summarized in Table 3.

Regarding MIB sfAPBI side effects, we did not report $G \geq 3$ late toxicity confirming the safety of this approach already reported by others (Table 3). However, Sacchini et al. had to decrease the per-operative delivered dose from 20 Gy to 18 Gy due to the unexpectedly high-rate of acute toxicity.

Specifically for elderly patients presenting with a low-risk positive hormonal status breast cancer, the omission of adjuvant radiation therapy was suggested in order to alleviate the treatment. In those phase III randomized trials (Surgery + hormonal therapy with or without adjuvant WBI), there was no significant difference in terms of overall survival between irradiated and non-irradiated patients $[28,29]$. However, there was a significant over-risk of local recurrence for patient without adjuvant breast irradiation. In elderly patients, the impact on functional status must be taken in account in treatment decision. The GERICO-O3 phase II trial aimed to evaluate the impact on functional status of MIB APBI in a cohort of 46 elderly women (median age: 74 years). Activity Daily Living (ADL) and Instrumental Activity Daily Living (IADL) scales were evaluated before and after ABPI. The scores remained unchanged at 6 and 12 months after APBI confirming no deleterious impact of MIB APBI [30].

\section{Conclusion}

We reported promising and encouraging clinical outcome of a post-operative single fraction of MIB ABPI in the elderly. This approach leads to consider a sfAPBI as an attractive alternative to intra-operative radiation therapy while all the patients will be good candidates for 
Table 3 Very hypo-fractionnated APBI discribed in the litterature

\begin{tabular}{|c|c|c|c|c|c|c|c|c|c|c|c|c|}
\hline Authors & Year & $\begin{array}{l}\# \\
\text { pts }\end{array}$ & $\begin{array}{l}\text { MFU } \\
\text { (months) }\end{array}$ & $\begin{array}{l}\text { APBI } \\
\text { techniques }\end{array}$ & $\begin{array}{l}\text { Total dose } \\
\text { (Gy) }\end{array}$ & $\begin{array}{l}D / f \\
(G y)\end{array}$ & $\begin{array}{l}\text { AG3 to } \\
(\%)\end{array}$ & $\begin{array}{l}\text { LG3 tox } \\
(\%)\end{array}$ & $\begin{array}{l}\mathrm{LF} \\
(\%)\end{array}$ & $\begin{array}{l}\text { RF } \\
(\%)\end{array}$ & $\begin{array}{l}\mathrm{DM} \\
(\%)\end{array}$ & $\begin{array}{l}\text { Ex/good cosmetic result } \\
(\%)\end{array}$ \\
\hline Sacchini & 2008 & $\begin{array}{l}18 / \\
34\end{array}$ & 31 & HDR & $20 / 18$ & $20 / 18$ & 7.7 & - & 0 & - & - & c \\
\hline Khan & 2013 & 30 & 11 & Balloon ${ }^{a}$ & 28 & $\begin{array}{l}7 \\
(\mathrm{BID})\end{array}$ & 0 & 0 & - & - & - & - \\
\hline Wilkinson & $\begin{array}{l}2012 / \\
17\end{array}$ & 45 & 74 & Balloon ${ }^{b}$ & 28 & $\begin{array}{l}7 \\
(\mathrm{BID})\end{array}$ & 13.3 & 2 & 0 & 0 & 0 & 91 \\
\hline Showalter & 2016 & 28 & 6 & HDR IORT & 12.5 & 12.5 & 0 & - & - & - & - & 93 \\
\hline Hannoun-Levi & 2017 & 26 & 37 & $\mathrm{HDR}_{\mathrm{MIB}}$ & 16 & 16 & 7.6 & 0 & 0 & 0 & - & 88 \\
\hline Latorre & 2018 & 20 & 24 & $\mathrm{HDR}_{\mathrm{MIB}}$ & 18 & 18 & 0 & 0 & 0 & 0 & 5 & 80 \\
\hline Present study & 2018 & 48 & 40 & $\mathrm{HDR}_{\mathrm{MIB}}$ & 16 & 16 & 6.3 & 0 & 0 & 0 & 0 & 100 \\
\hline
\end{tabular}

${ }^{\mathrm{a}}$ Contura $^{\mathrm{TM}}$

${ }^{\mathrm{b}}$ Mammosite ${ }^{\mathrm{TM}}$

${ }^{c}$ Cosmetic results were better with $18 \mathrm{~Gy}$ compared to $20 \mathrm{~Gy}$

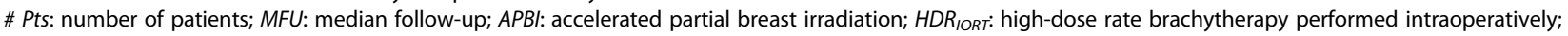
MIB: multicatheter interstitial high-dose rate brachytherapy; D/f: dose per fraction; AG3 tox: acute $\geq$ Grade 3 toxicity; LG3 tox: late $\geq$ Grade 3 toxicity; LF: local

failure; RF: regional failure; DM: distant metastasis; Ex/good cosmetic: percentages of excellent and good cosmetic results

$\mathrm{APBI}$ in regards to the post-operative pathological report. SfAPBI allows to drastically reducing the number of transportations and could benefit to the patients by decreasing fatigue and to the society by lowering cost related to transportations. More mature results (number of patients and follow-up) are needed to confirm the results.

\section{Abbreviations \\ ADL: Activity Daily Living; APBI: Accelerated partial breast irradiation; ASTRO: American Society of Radiation Oncology; DNR: Dose non- homogeneity ratio; GEC-ESTRO: Groupe Européen de Curiethérapie of the European Society for Radiotherapy and Oncology; HDR: High-dose rate; IADL: Instrumental Activity Daily Living; IORT: Intraoperative radiation therapy; LRFS: Local relapse-free survival; MIB: Multicatheter interstitial brachytherapy; OS: Overall survival; PS: Performans Status; RRFS: Regional relapse-free survival; sfAPBI: Single fraction APBl; SS: Specific survival; WBI: Whole breast irradiation}

\section{Availability of data and materials}

The datasets used and/or analyzed during the current study are available from the corresponding author on reasonable request.

\section{Authors' contributions}

RK: acquisition of data and analysis, manuscript writing and final approval, MEC: data analysis and final approval, JG: statistical analysis and final approval, MG: data analysis and final approval, LM: acquisition of data and analysis and final approval, DLCK: data analysis and final approval, JMHL: Study concept, design, acquisition of data and analysis, manuscript writing and final approval.

\section{Ethics approval and consent to participate}

This study was approved by the local ethic committee of the Antoine Lacassagne Cancer Center.

\section{Consent for publication}

Institutional consent form was obtained.

\section{Competing interests}

The authors declare that they have no competing interests.

\section{Publisher's Note}

Springer Nature remains neutral with regard to jurisdictional claims in published maps and institutional affiliations.

\section{Author details}

${ }^{1}$ Department of Radiation Oncology, Centre Antoine Lacassagne - University of Cote d'Azur, 33 avenue de Valombrose, 06000 Nice, France. ${ }^{2}$ Biostatistic unit, Centre Antoine-Lacassagne, 33 av de Valombrose, 06189 Nice, France.

Received: 5 June 2018 Accepted: 29 August 2018

Published online: 12 September 2018

\section{References}

1. Fisher B, Anderson S, Bryant J, et al. Twenty-year follow-up of a randomized trial comparing Total for the treatment of invasive breast Cancer. N Engl J Med. 2002;347:1233-41.

2. Darby S, McGale P, Correa C, et al. Effect of radiotherapy after breastconserving surgery on 10-year recurrence and 15-year breast cancer death: meta-analysis of individual patient data for 10801 women in 17 randomised trials. Lancet. 2011;378:1707-16.

3. Trialists TS. The UK Standardisation of breast radiotherapy (START) trial a of radiotherapy hypofractionation for treatment of early breast cancer: a randomised trial. Lancet Oncol. 2008:9:331-41.

4. START Trialists' Group TST, Bentzen SM, Agrawal RK, et al. The UK standardisation of breast radiotherapy (START) trial B of radiotherapy hypofractionation for treatment of early breast cancer: a randomised trial. Lancet. 2008;371:1098-107.

5. Whelan T. Randomized trial of breast irradiation schedules after lumpectomy for women with lymph node-negative breast Cancer. CancerSpectrum Knowl Environ. 2002:94:1143-50.

6. Correa C, Harris EE, Leonardi MC, et al. Accelerated partial breast irradiation: executive summary for the update of an ASTRO evidence-based consensus statement. Pract Radiat Oncol. 2017;7:73-9.

7. Polgár C, Van Limbergen E, Pötter R, et al. Patient selection for accelerated partial-breast irradiation (APBI) after breast-conserving surgery: recommendations of the Groupe Européen de Curiethérapie-European Society for Therapeutic Radiology and Oncology (GEC-ESTRO) breast cancer working group based on clinical evidence (2009). Radiother Oncol. 2010;94:264-73.

8. Coles CE, Griffin CL, Kirby AM, et al. Partial-breast radiotherapy after breast conservation surgery for patients with early breast cancer (UK IMPORT LOW trial): 5-year results from a multicentre, randomised, controlled, phase 3, non-inferiority trial. Lancet. 2017:390:1048-60.

9. Strnad V, Ott OJ, Hildebrandt G, et al. 5-year results of accelerated partial breast irradiation using sole interstitial multicatheter brachytherapy versus whole-breast irradiation with boost after breast-conserving surgery for low- 
risk invasive and in-situ carcinoma of the female breast : a randomised, phase 3, non-inferiority trial. Lancet. 2016;387:229-38.

10. Hannoun-Lévi JM, Cham Kee DL, Gal J, et al. Accelerated partial breast irradiation for suitable elderly women using a single fraction of multicatheter interstitial high-dose-rate brachytherapy: early results of the single-fraction elderly breast irradiation (SiFEBI) phase I/II trial. Brachytherapy. 2018;17:407-14.

11. Genebes C, Chand M-E, Gal J, et al. Accelerated partial breast irradiation in the elderly: 5 -year results of high-dose rate multi-catheter brachytherapy. Radiat Oncol. 2014;9:115.

12. Strnad V, Major T, Polgar C, et al. ESTRO-ACROP guideline: Interstitial multicatheter breast brachytherapy as Accelerated Partial Breast Irradiation alone or as boost - GEC-ESTRO Breast Cancer Working Group practical recommendations. Radiother Oncol. 2018; in press

13. Strnad V, Hannoun-Levi J-M, Guinot J-L, et al. Recommendations from GEC ESTRO breast Cancer working group (I): target definition and target delineation for accelerated or boost partial breast irradiation using multicatheter interstitial brachytherapy after breast conserving closed cavity surgery. Radiother Oncol. 2015;115:342-8.

14. Haviland JS, Owen JR, Dewar JA, et al. The UK standardisation of breast radiotherapy (START) trials of radiotherapy hypofractionation for treatment of early breast cancer: 10-year follow-up results of two randomised controlled trials. Lancet Oncol. 2013;14:1086-94.

15. Dutreix J, Cosset JM, Girinsky T. Biological equivalency of high single doses used in intraoperative irradiation. Bull Cancer Radiother. 1990;77: 125-34.

16. Wheldon TE, Deehan C, Wheldon EG, Barrett A. The linear-quadratic transformation of dose-volume histograms in fractionated radiotherapy. Radiother Oncol. 1998;46:285-95.

17. Trotti A, Colevas AD, Setser A, et al. CTCAE v3.0: development of a comprehensive grading system for the adverse effects of cancer treatment. Semin Radiat Oncol. 2003;13:176-81.

18. Harris JR, Levene MB, Svensson G, Hellman S. Analysis of cosmetic results following primary radiation therapy for stages I and II carcinoma of the breast. Int J Radiat Oncol Biol Phys. 1979;5:257-61.

19. Chand-Fouché M, Hannoun-Lévi JM. State of the art and perspectives of accelerated partial breast irradiation in 2014. Cancer Radiother. 2014;18: 693-700.

20. Vaidya JS, Joseph DJ, Tobias JS, et al. Targeted intraoperative radiotherapy versus whole breast radiotherapy for breast cancer (TARGIT-A trial): an international, prospective, randomised, non-inferiority phase 3 trial. Lancet. 2010:376:91-102.

21. Cozzi S, Laplana M, Najjari D, et al. Advantages of intraoperative implant for interstitial brachytherapy for accelerated partial breast irradiation either frail patients with early-stage disease or in locally recurrent breast cancer. J Contemp Brachytherapy. 2018;10:97-104.

22. Hannoun-Levi JM, Courdi A, Marsiglia H, Namer M, Gerard JP. Breast cancer in elderly women: is partial breast irradiation a good alternative? Breast Cancer Res Treat. 2003:81:243-51.

23. Latorre JA, Galdós P, Buznego LA, et al. Accelerated partial breast irradiation in a single $18 \mathrm{~Gy}$ fraction with high-dose-rate brachytherapy: preliminary results. J Contemp Brachytherapy. 2018;10:58-63.

24. Sacchini V, Beal K, Goldberg J, Montgomery L, Port E, McCormick B. Study of quadrant high-dose intraoperative radiation therapy for early-stage breast cancer. Br J Surg. 2008:95:1105-10.

25. Khan AJ, Vicini FA, Brown S, et al. Dosimetric feasibility and acute toxicity in a prospective trial of ultrashort-course accelerated partial breast irradiation (APBI) using a multi-lumen balloon brachytherapy device. Ann Surg Oncol. 2013;20:1295-301.

26. Ben WJ, Martinez AA, Chen PY, et al. Four-year results using balloon-based brachytherapy to deliver accelerated partial breast irradiation with a 2-day dose fractionation schedule. Brachytherapy. 2012;11:97-104.

27. Wilkinson JB, Chen PY, Wallace MF, et al. Six-year results from a phase I/II trial for Hypofractionated accelerated partial breast irradiation using a 2day dose schedule. Am J Clin Oncol. 2017;1 https://doi.org/10.1097/ COC.0000000000000402.

28. Hughes KS, Schnaper LA, Bellon JR, et al. Lumpectomy plus tamoxifen with or without irradiation in women age 70 years or older with early breast cancer: long-term follow-up of CALGB 9343. J Clin Oncol. 2013;31:2382-7.

29. Kunkler $\mathrm{H}$, Williams $\mathrm{LJ}$, Jack WJL, Cameron DA, Dixon JM. Breast-conserving surgery with or without irradiation in women aged 65 years or older with early breast cancer (PRIME II): a randomised controlled trial. Lancet Oncol. 2015;16:266-73.

30. Hannoun-Levi J-M, Gourgou-Bourgade S, Belkacemi Y, et al. GERICO-03 phase II trial of accelerated and partial breast irradiation in elderly women: feasibility, reproducibility, and impact on functional status. Brachytherapy. 2013;12:285-92
Ready to submit your research? Choose BMC and benefit from:

- fast, convenient online submission

- thorough peer review by experienced researchers in your field

- rapid publication on acceptance

- support for research data, including large and complex data types

- gold Open Access which fosters wider collaboration and increased citations

- maximum visibility for your research: over $100 \mathrm{M}$ website views per year

At BMC, research is always in progress.

Learn more biomedcentral.com/submissions 